\title{
Sudden and unexpected death between 1 and 5 years
}

\author{
D P SOUTHALL, V STEBBENS, AND E A SHINEBOURNE
}

Department of Paediatrics, Cardiothoracic Institute, Brompton Hospital, London

SUMMARY Of a population of 9856 children followed up from birth, 9251 of whom underwent 24 hour tape recordings of electrocardiograms and abdominal wall breathing movements during early infancy, five died suddenly and unexpectedly at home at ages ranging from 16 months to 4 years. Postmortem examination, including full histological and microbiological investigations, failed to identify abnormalities ordinarily associated with death in all five cases. Two of the children were known to have had frequent cyanotic episodes and died during these events. In the three remaining cases there was no previous history of cyanotic or apnoeic episodes. The death of one of these three children was seen by his parents and the clinical features suggested that apnoea rather than a cardiac arrhythmia was the primary mechanism for his death.

As in infancy, sudden and unexpected death for which no adequate cause is found at necropsy seems to constitute a major component of mortality between 1 and 5 years.

In a large prospective, population based, nonintervention study into the sudden infant death syndrome (SIDS), preliminary details of which have been already reported, 9856 infants were recruited. All were tagged by the Office of Population Censuses and Surveys at the central National Health Service register so that any deaths in the study group, no matter where they occurred in the United Kingdom, would be notified. Five years later it has become apparent that five of the 15 deaths between 1 and 5 years were sudden, unexpected, and without adequate explanation at postmortem examination. An analysis of the clinical histories and modes of death in these five cases forms the substance of this report.

Details of the population recruited and of deaths occurring up to five years later

Two population based samples of full term infants ( $\geqslant 37$ weeks' gestation) were recruited. The first sample consisted of infants born with a birth weight of $2500 \mathrm{~g}$ or more in three hospitals in England between July 1980 and June $1981(n=7496)$. The second sample consisted of full term infants born with a birth weight of $2500 \mathrm{~g}$ or less in six hospitals, including the three already mentioned between October 1979 and December $1981(\mathrm{n}=559)$. Similarly, premature infants ( $\leqslant 36$ weeks' gestation) admitted to the special care baby units of these six hospitals during the same period were recruited $(n=1801)$.
A small number of infants were excluded due to severe illness from birth and subsequent death before 1 month of age without an intervening period of recovery. The causes of death in this group included severe congenital anomalies, complications of extreme prematurity, and birth asphyxia.

Up to December 1986 there have been 64 deaths, 38 in the full term infants and 26 in the previously premature infants. Of these 64 deaths, 49 occurred during infancy. An adequate cause of death was recorded in 22 , but 27 died suddenly, unexpectedly, and without adequate explanation at postmortem examination (cot death or SIDS). This group has been described previously. ${ }^{1}$

Of the children alive at the end of their first year, 15 died before their fifth birthday. An adequate cause of death was reported in 10 (Table), but in five death was sudden, unexpected, and without adequate explanation at postmortem examination. Of the postmortem examinations, three were performed by a paediatric pathologist and all five included histological and microbiological investigations.

Case histories of sudden, unexpected, and unexplained deaths

Case 1 had no previous history of cyanotic episodes but died during an apnoeic event associated with rapidly developing cyanosis. Cases 2 and 3 had previous histories of cyanotic episodes and died during a typical episode. Cases 4 and 5 had no 
Table Causes of death between 1 and 5 years of age in a group of 9856 children

\begin{tabular}{|c|c|c|c|c|}
\hline \multirow{2}{*}{$\begin{array}{l}\text { Population } \\
\text { studied }\end{array}$} & \multicolumn{2}{|c|}{ Explained deaths } & \multirow{2}{*}{$\begin{array}{l}\text { Sudden and } \\
\text { unexpected deaths } \\
\text { without explanation } \\
\text { at postmortem } \\
\text { examination }\end{array}$} & \multirow[t]{2}{*}{ Total } \\
\hline & No & Cause & & \\
\hline $\begin{array}{l}\text { Full term infants } \\
\text { of normal } \\
\text { birth weight } \\
(n=7496)\end{array}$ & 3 & $\begin{array}{l}\text { (1) Cardiac failure/airway obstruction: varicella infection. } \\
\text { (2) Hepatic failure, biliary atresia. } \\
\text { (3) Accidental (drowning). }\end{array}$ & 3 & 6 \\
\hline $\begin{array}{l}\text { Full term infants of low } \\
\text { birth weight and admitted } \\
\text { to special care baby } \\
\text { unit }(n=559)\end{array}$ & 1 & $\begin{array}{l}\text { Bronchopneumonia, } \\
\text { Niemann-Pick`s syndrome }\end{array}$ & 2 & 3 \\
\hline $\begin{array}{l}\text { Preterm infants } \\
(\mathrm{n}=1801)\end{array}$ & 6 & $\begin{array}{l}\text { (1) Bronchitis: cerebral defect due to extreme prematurity. } \\
\text { (2) Congenital heart disease. } \\
\text { (3)-(5) Accidental: (3) hanging: (4) road traffic accident: and } \\
\text { (5) inhalation of smoke and multiple burns. } \\
\text { (6) Bronchopneumonia: cerebral defect with bulbar palsy. }\end{array}$ & 0 & 6 \\
\hline Total $\quad(n=9856)$ & 10 & & 5 & 15 \\
\hline
\end{tabular}

previous cyanotic episodes and were found dead after they had been seen to be asleep. The mode of death in cases 4 and 5 was similar to that in most sudden, unexpected, and unexplained infant deaths (cot deaths).

Case 1. This boy died at 4 years and was the second of three children. He was born after an uncomplicated pregnancy at 40 weeks' gestation, with a birth weight of $3280 \mathrm{~g}$ and an Apgar score of 9 at one minute. During pregnancy his mother did not smoke or take any medication. He was breast fed and fully immunised. Apart from minor respiratory tract illness, he was well until 4 years 4 months, when he died suddenly at home.

On the day of his death he was well and had shown no signs of a respiratory tract infection or any other illness. At about $1800 \mathrm{~h}$ he was standing watching television when his brother pushed him and he fell lightly against the wall. He recovered posture but ran into the kitchen where his mother and father were preparing dinner. He was pointing to his chest and his mouth was wide open. He did not make any audible sounds but within 10-15 seconds of the fall became rapidly more cyanosed. At around 20-30 seconds, when he was deeply cyanosed, he fell to the floor and lost consciousness. His father had recently undergone a course of training in resuscitation but, despite mouth to mouth airway pressure, could not inflate his chest for the first minute of his unconscious state. Thereafter, his chest suddenly inflated and continued to do so with each of his father's breaths. He did not recover, however, and by the time the family doctor arrived (15 minutes later) he was pronounced dead.
The only finding at postmortem examination was lung congestion with pulmonary oedema. No foreign body was found in the airway. The upper airway and cardiovascular system were structurally normal and no micro-organisms were detected on microbiological examination.

His younger brother, aged 14 months at the time of his brother's death, had suffered two cyanotic episodes after attempts to cry in frustration. In both cases he recovered with a gasp and did not lose consciousness.

Case 2. This girl, who died at 18 months, was born to a single mother who was 17 at the time of birth. Her mother had smoked eight cigarettes a day during the pregnancy, which was otherwise uncomplicated. She was born at 37 weeks' gestation, with a birth weight of $2450 \mathrm{~g}$ and an Apgar score of 10 at one minute. She had a hare lip and cleft soft palate.

At 3 weeks she was admitted for difficulties in feeding and an upper respiratory tract infection. At 3 months her hare lip was repaired. At 9 months she suffered a lower respiratory tract infection and was treated in hospital. At 16 months she ingested half a bottle of disinfectant with no apparent ill effects.

At 17 months she presented with two cyanotic episodes, each after an attempt to cry. After each of these episodes she became drowsy and, according to her mother, was disorientated. Her family doctor found no abnormalities on clinical examination. Two further episodes occurred, the first while she was being placed into her cot and the second while in her cot and thought to be asleep. In both latter episodes her mother stimulated her and she breathed in and recovered. 
She was admitted to hospital. No abnormalities were found on clinical examination and the following investigations were performed and yielded normal results: blood sugar concentration, full blood count, blood culture, lumbar puncture, and chest $x$-ray film. During this admission a cyanotic episode was observed by an experienced paediatric nurse. The child was playing, fell down, started to cry, then 'held her breath', and became rapidly and severely cyanosed. The episode ended with a gasp and she fell asleep afterwards. A diagnosis of 'cyanotic breath holding' was made, the mother reassured, and the child discharged.

Two weeks later she was found cyanosed in her cot. Her mother went to wake her and found her lying still, deeply cyanosed, and sweating profusely. She was stimulated by her mother and slowly recovered consciousness. During her journey to hospital in an ambulance, however, a further severe cyanotic episode occurred and she was given oxygen. This episode was accompanied by a loss of consciousness and convulsions. The morning of these episodes she had received a routine immunisation. She was admitted to hospital, largely at the request of the mother. The paediatrician explained that these were cyanotic 'breath holding' episodes and advised the mother that no treatment was necessary. At this time she remained drowsy. An eight channel electroencephalogram (EEG) was performed and showed no abnormalities. No further cyanotic episodes occurred and she was discharged home.

Five days later, while awake and being carried to bed by her mother, a further cyanotic episode occurred. Her mother ran to a nearby house with the child and the neighbour attempted mouth to mouth resuscitation. The police and ambulance men arrived and also attempted resuscitation but without success. She was pronounced dead on arrival at the hospital.

Postmortem examination showed a small child (weight $<3$ rd centile) with a mild upper respiratory tract infection and otitis media. There was pulmonary oedema and lung congestion, but no structural abnormality of the upper airway.

Case 3. This girl, who died at 2 years 10 months, was the first born and only child of the mother's second marriage (the mother was 40). Her father (aged 42) had no previous children but her mother had two children from her first marriage. There was no family history of cyanotic episodes. She was born at 38 weeks' gestation, with a birth weight of $2250 \mathrm{~g}$, after a pregnancy complicated by polyhydramnios and by emergency caesarean section for fetal distress during labour. The day after birth she underwent repair of a tracheo-oesophageal fistula with oesophageal atresia. She recovered well from this procedure, was breast fed, and was discharged home at 1 month.

At 3 months she began to suffer cyanotic episodes, which continued thereafter with a frequency varying from three per week to one per month until her death. These episodes were witnessed by paediatricians and by nursing staff. Most were associated with eating or drinking, some occurred after an attempt to cry in association with noxious stimuli, and others occurred during sleep. For each cyanotic episode, the first event detected by the parents and hospital staff was an audible expiratory grunt. This was followed by the extremely rapid onset (within five to 10 seconds) of cyanosis. There were no apparent breathing movements, she seemed to be 'breath holding in expiration', and by 20 seconds she was deeply cyanosed and seemed unconscious. Observations by medical staff during cyanotic episodes showed no evidence of obstructed inspiratory efforts. Recovery was heralded by the sudden onset of an inspiratory breath, after which the cyanosis would decrease, although it might take up to one minute to clear completely. She would then remain hypotonic and drowsy for several hours.

Her parents never left her unattended, and she slept next to their bed. Sometimes she recovered spontaneously from a cyanotic episode without losing consciousness. For most episodes she was given mouth to mouth resuscitation or positive pressure inflation by an Ambu-bag and face mask.

In between episodes she was well apart from a loud expiratory grunt, which was most pronounced during exercise or excitement.

At 10 months she was admitted for further investigation of the cyanotic episodes. A barium swallow examination showed 'minimal and probably insignificant reflux' and the oesophagus seemed to be of normal calibre (a second barium swallow examination performed at 22 months failed to show any reflux). At bronchoscopy there seemed to be some anteroposterior narrowing of the lower third of the trachea, and cinefluoroscopy of the trachea during quiet breathing showing some evidence of narrowing during expiration. A diagnosis of tracheomalacia was considered and she was treated by aortopexy. ${ }^{2}$ At subsequent bronchoscopy and cinefluoroscopy two weeks postoperatively the trachea seemed wider. Nevertheless, the aortopexy made no impact on the frequency or severity of the cyanotic episodes, which on two occasions occurred despite nasotracheal intubation.

During periods of unconsciousness associated with the most prolonged episodes of cyanosis, she developed convulsive movements and was some- 
times incontinent of urine. An EEG showed no abnormalities and treatment with anti-epileptic drugs failed to reduce or modify her cyanotic episodes. Her paediatrician considered that the convulsions were secondary to hypoxaemia and at 18 months the treatment with anti-epileptic drugs was stopped. A diagnosis of reflex anoxic seizures ${ }^{3}$ was also considered and she was treated with atropine $150 \mathrm{mg}$ three times daily. This also failed to modify the frequency or severity of cyanotic episodes.

Although developmental assessments, including one performed a week before death, yielded normal results, a minimal right sided hemiparesis was identified at 2 years. This was thought to have resulted from a particularly severe and prolonged episode of hypoxia that occurred at 18 months. At the time of this severe episode, she was resident for three days in the children's ward to cover the time after a routine immunisation.

Her fatal cyanotic episode occurred at 2 years 10 months when she was in a restaurant. She had just finished eating a sponge cake and a glass of orange squash when she looked up at her mother and stopped breathing. Her facial expression indicated to her mother that she was about to have a cyanotic episode. She became rapidly cyanosed (within 10 seconds) and her mother lifted her out of the chair, carried her outside the restaurant, placed her on the pavement, and gave mouth to mouth resuscitation. She started to breathe but then stopped again. Despite the efforts of the ambulancemen she was dead on arrival at the hospital.

A postmortem examination showed pulmonary oedema and a small area of oesophageal dilatation at the site of the repair of the tracheo-oesophageal fistula. The airway was structurally normal with no evidence of stenosis or malacia of the trachea or right or left main bronchus.

Case 4. This boy, who died at 3.5 years, was the second born of three children. His mother was 26 years old at his birth, which followed a pregnancy complicated by iron deficiency anaemia and a urinary tract infection. His mother did not smoke during pregnancy. He was born at 38 weeks' gestation, with a birth weight of $3060 \mathrm{~g}$ and an Apgar score of 8 at one minute. Before death he suffered only minor illnesses typical of early childhood.

On the day of death he was put to bed at around $1830 \mathrm{~h}$. He shared the bedroom with his older brother, who was aged 5 years. At around $2300 \mathrm{~h}$ his mother went, as usual, to take him to the toilet and found him dead.

At postmortem examination his weight was $14 \mathrm{~kg}$ (10-25th centile) and apart from patches of pulmonary oedema, there were no abnormalities that were known to be associated with sudden death. In particular, the airway was structurally normal. The pathologist recorded that the cause of death was unknown.

His older brother had suffered cyanotic episodes between 1 and 3 years of age. In one of these episodes he had lost consciousness.

Case 5. This boy, who died at 16 months, was the first child. His mother was aged 20 at his birth, which followed a pregnancy complicated only by maternal smoking (10 a day) and an allergic rash on the legs treated by chlorpheniramine for the last month of pregnancy. He was born at 40 weeks' gestation, with a birth weight of $2700 \mathrm{~g}$ and an Apgar score of 10 at one minute. Up until the time of death, he was healthy, breast fed until 14 months, and fully immunised.

The day before death the family had travelled to stay with his grandparents. He was placed in a travelling cot for his usual afternoon sleep at $1400 \mathrm{~h}$. The cot was in the parents' bedroom, and this was kept adequately warm by an electric heater. Three hours later his mother went to wake him and found him dead.

A postmortem examination failed to explain death. Partial atelectasis of both lower lobes of the lungs and pulmonary oedema and dilatation of the right ventricle were the only findings. The airway was structurally normal.

Shortly after the death his mother attempted suicide but was successfully resuscitated. She now has another child, who is well.

\section{Results of the analysis of 24 hour tape recordings on the five sudden unexplained deaths}

Twenty four hour tape recordings were obtained during the first two months of life on all five cases; in case 1 at 7 and 47 days, in case 2 at 1 day, in case 3 at 16 and 52 days, in case 4 at 2 days, and in case 5 at 21 days.

None of these recordings showed a cardiac arrhythmia, pre-excitation, or a prolonged QT interval. None showed prolonged apnoeic pauses. When compared with age and birth weight matched controls none showed abnormal mean heart and respiratory rates, ${ }^{45}$ but case 4 showed abnormally increased levels of short apnoeic pauses and periodic breathing at 16 days. $^{6}$

\section{Discussion}

Sudden unexpected and unexplained deaths without 
adequate explanation at postmortem examination (the sudden infant death syndrome (SIDS)) constitute a major proportion of infant mortality during the first year of life. United Kingdom figures show that about $45 \%$ of all deaths during infancy and after the first week of life are categorised as SIDS. ${ }^{7}$

These five case reports exemplify what might be termed sudden unexplained childhood death. The five deaths occurred in the four years after infancy in a population of just under 10000 followed up from birth. The frequency of this entity in this sample followed to the end of the fourth year of life is about $0 \cdot 125$ per 1000 (each year), roughly 16 times less than the incidence of SIDS (from 1.95 per 1000 live births). ${ }^{7}$ Sudden deaths without explanation represent an important component of mortality in early childhood, as well as in infancy, accounting here for one third of the 1 to 5 year mortality.

Our original sample of infants was biased to include a higher proportion of low birthweight and preterm subjects, and therefore the prevalence of sudden unexplained child death in our population may not necessarily represent the true incidence in the United Kingdom. Nevertheless, three of the five sudden, unexplained deaths occurred in full term, normal birthweight infants.

In cases 4 and 5 the mode of death was similar to that of most SIDS victims. Apparently healthy children were found dead in bed. The tragedies were all the worse as the children were at an age when the possibility of sudden death is rarely considered by parents and when the children were established members of the family.

In case 1 there was no warning of the fatal cyanotic event. An upright posture was maintained during the first 20 seconds. As a cardiac arrhythmia would usually be accompanied by a fall in cardiac output and hypotension an apnoeic mechanism is more likely. The latter may have resulted from acute airway obstruction, ${ }^{8}$ a seizure in the limbic area, ${ }^{9}$ or prolonged expiratory apnoea ${ }^{10-12}$ (cyanotic 'breath holding'). ${ }^{13}$

In case 2 the typical history and observation of the cyanotic episodes confirmed a diagnosis of cyanotic 'breath holding'. ${ }^{10-13}$ There was no history of stridor, ribcage retraction, or any of the other features of airway obstruction in this infant. Moreover, we could find no data that described an increased incidence of cyanotic episodes in patients with clefts in the soft palate. Prolonged expiratory apnoea has been identified as the mechanism for expiratory cyanotic breath holding episodes by Gauk $^{10}$ and from our own continued experience in 10 infants and young children. ${ }^{11-12}$ The hallmark of this condition is the rapidity of onset and severity of the arterial hypoxaemia. Episodes are usually trig- gered by an experience that results in an attempt to cry. The child opens his mouth wide, makes no audible sound, and is cyanosed within five to 15 seconds. Breathing movements are ineffective in that there is no inspiratory airflow. After 20-30 seconds, when cyanosis is profound, the child will lose consciousness and may start convulsing. If the child is standing at the onset of the episode he may move towards help but will eventually fall down as hypoxaemia progresses. Recovery, if spontaneous, usually occurs with a large inspiratory effort or gasp. Respiratory function tests and other investigations may be normal between apnoeic episodes. The cyanotic episodes typically consist of a short initial phase of absent respiratory efforts followed by active expiratory efforts and rapid and severe arterial hypoxaemia. ${ }^{10-12}$ Upper airway closure also occurs, ${ }^{11} 12$ but we emphasise that this is not the primary cause of the apnoea but an associated response: prolonged expiratory apnoeic events occur despite the bypassing of the upper airway. ${ }^{11} 12$ As case 2 died during a typical cyanotic episode it can be concluded that the cause of her death was prolonged expiratory apnoea.

The cause of death in case 3 is less straightforward. Previous reports on the cyanotic episodes that may often follow the repair of a tracheooesophageal fistula have attributed the hypoxaemia to airway obstruction from tracheomalacia. ${ }^{2}$ The extremely rapid onset of severe arterial hypoxaemia is, however, difficult to explain on the basis of tracheal obstruction and raises the possibility that, in this case, and possibly in others after tracheooesophageal fistula repair, prolonged expiratory apnoea may have been responsible for the cyanotic episodes. In this latter condition the rapid hypoxaemia is thought to follow apnoea at low lung volume where there is a major mismatch between ventilation and perfusion. ${ }^{11}{ }^{12}{ }^{14}$ At the onset of apnoea from airway obstruction lung volume would not be expected to be below functional residual capacity and there should be enough oxygen in the lungs to delay onset of cyanosis for 30 to 40 seconds. The continuation of cyanotic episodes despite nasotracheal intubation in this child rules out upper airway obstruction. Other features of the cyanotic episodes in case 3 that support expiratory rather than lower airway obstructive apnoea include the lack of postmortem evidence of tracheomalacia and the expiratory rather than the inspiratory efforts noted by medical staff during cyanosis. Aortopexy also failed to reduce the frequency or severity of cyanotic episodes. In case 3 many episodes of cyanosis followed eating or drinking, raising the possibility that some of the apnoeic episodes might have been triggered by food or liquid within the 
oesophagus. Stimulation of oesophageal receptors has been shown to produce bronchoconstriction, ${ }^{15}$ and in the presence of unstable alveoli this might produce a reduction in functional residual capacity, thus triggering an episode. Aspiration of food into the trachea may also have triggered severe lower airway obstruction. Coughing from bronchial $\mathrm{C}$ fibre (irritant) receptor stimulation was not, however, a feature of the cyanotic episodes.

In a previous prospective study the incidence of cyanotic 'breath holding' episodes was reported to be $2 \cdot 8 \%,{ }^{13}$ most $(80 \%)$ having ceased by 6 years. From these figures, 276 cases might have been expected in our sample of 9856 children, and it will be valuable to ascertain whether our ongoing follow up of this present population confirms this. Nevertheless, most have therefore not died, which perhaps explains why the condition is thought to be benign. Our present findings that prolonged expiratory apnoea was almost certainly responsible for death in case 2 and possibly responsible in case 3 indicate that the condition may sometimes not be benign, a view supported by the case described by Paulson. ${ }^{16}$ Apart from death, severe neurodevelopmental disorders may follow these episodes. ${ }^{11}$

In conclusion, one third of deaths in this sample of children aged 1 to 5 years were sudden and without adequate explanation at postmortem examination. Prolonged expiratory apnoea was responsible for death in at least one of our five cases.

This study was funded by the British Heart Foundation, the Hayward Foundation, the Foundation for the Study of Infant Death (FSID), and the people of Brighton and Doncaster. Mrs V Stebbens was funded by FSID and the Nuffield Foundation. Dr Southall was funded by the British Heart Foundation, the National SIDS Foundation, the Joseph Levy Foundation, the Waring Scholarship, Healthdyne, and Nellcor. We thank Dr Y Sivan for advice on the manuscript. We are extremely grateful to $\mathrm{K}$ Sowton for her help with this manuscript.

\section{References}

I Southall DP, Richards JM, de Swict M, et al. Identification of infants destined to dic unexpectedly during infancy: evaluation of predictive importance of prolonged apnoea and disorders of cardiac rhythm or conduction. First report of a multicentred prospective study into the sudden infant death syndrome. $\mathrm{Br}$ Med J 1983;286:1092-6.

2 Schwartz MZ, Filler RM. Tracheal compression as a cause of apnea following repair of tracheo oesophageal fistula: treatment by aortopexy. J Pediatr Surg 1980;15:842-8.

${ }^{3}$ Stephenson JBP. Reflex anoxic seizures ('white breathholding'): non-epileptic attacks. Arch Dis Child 1978;53: 193-200.

4 Richards JM, Alexander JR, Shinebourne EA, de Swiet M, Wilson AJ, Southall DP. Sequential 22 hour profiles of breathing pattern and heart rate in 110 full-term infants during their first 6 months of life. Pediatrics 1984:74:763-77.

5 Wilson AJ, Stevens V. Franks CI, Alexander JR, Southall DP. Respiratory and heart rate patterns in infants destined to die of the sudden infant death syndrome. Br Med J 1984;290:497-501.

6 Southall DP, Richards JM, Stebbens V, Wilson AJ, Taylor V. Alexander JR. Cardiorespiratory function in 16 fullterm infants with sudden infant death syndrome. Pediatrics 1986;78:787-96.

${ }^{7}$ Golding J. Limenik S, MacFarlane A. Sudden infant death. Patterns, puzzles and problems. London: Open Books Publishing, 1985.

* Guilleminault C, Ariagno RL, Forno LS, Nagel L, Baldwin R, Owen M. Obstructive sleep apnea and near miss for SIDS: 1 report of an infant with sudden death. Pediatrics 1979;63: $837-43$.

" Watanabe K, Hara K, Hakamada S, et al. Seizures with apnea in children. Pediatrics 1982;70:87-90.

10 Gauk EW, Kidd L, Prichard JS. Mechanism of seizures associated with breath-holding spells. N Engl J Med 1963;268: 1436-41.

"Southall DP, Talbert DG, Johnson P, et al. Prolonged expiratory apnoea - a disorder resulting in episodes of severe arterial hypoxaemia in infants and young children. Lancet 1985;ii: 571-7.

12 Southall DP. Talbert DG. Sudden atelectasis apnoea braking syndrome (SAABS). Reviews in Pulmonary Pharmacology. (In press).

13 Lombroso CT, Lerman P. Breath holding spells (cyanotic and pallid infant syncope). Pediatrics 1967;39:563-81.

14 Southall DP, Talbert DG. Johnson P, et al. Prolonged expiratory apnoea. Lancet 1985;ii:1125-6.

15 Mansfield LE, Stein MR. Gastro-oesophageal reflux and asthma - demonstration of a possible reflex mechanism. Ann Allergy 1978;41:224-6.

16 Paulson G. Breath holding spells - a fatal case. Dev Med Child Neurol 1963;5:246-51.

Correspondence to Dr D P Southall. Department of Paediatrics, Cardiothoracic Institute, Brompton Hospital, Fulham Road, London SW3 6HP.

Received 30 January 1987 